\title{
7,8-Dihydroxyflavone Protects PC12 Cells against MPP+-Induced Cytotoxicity by Heme Oxygenase-1
}

\author{
Yu Song ${ }^{1}$, Xiaohua $\operatorname{Han}^{1}$
}

\author{
${ }^{1}$ Department of Physiology, Medical College of Qingdao University, Qingdao 266071, China
}

\begin{abstract}
DHF), a newly-selective tyrosine kinase receptor B (TrkB) agonist, has been well studied for its neurotrophic functions. Our previous study has shown that 7,8-DHF could exert potent neuroprotective effect against 6-hydroxydopamine (6-OHDA)-induced cytotoxicity in PC12 cells without TrkB receptor expression. Howerer, this phenomenon induced by 1-methyl-4-phenylpyridinium $\left(\mathrm{MPP}^{+}\right)$has not been elucidated. This study is designed to investigate whether heme oxygenase-1(HO-1)signaling pathway mediate the protection by 7,8-DHF. The results were as follows: MTT assay showed that treatment with $\mathrm{MPP}^{+}$significantly suppressed the cell viability. 7,8-DHF pretreatment suppressed $\mathrm{MPP}^{+}$-induced cytotoxicity and providing strong protection in PC12 cells. Incubation of 7,8-DHF with the PC12 cells up to $6 \mathrm{~h}$ showed it up-regulated the HO-1 expression. Moreover, the PC12 cells pretreatment with ZnPP were found to partially block the protective effect of 7,8-DHF. The present results provided the evidence that 7,8-DHF could protect the PC12 cells against $\mathrm{MPP}^{+}$-induced cytotoxicity through $\mathrm{HO}-1$ pathway.
\end{abstract}

Keywords: 7,8-Dihydroxyflavone, 1-Methyl-4-Phenylpyridinium, PC12 Cells, Heme Oxygenase-1, ZnPP

\begin{abstract}
Introduction
Parkinson's disease (PD), a progressive neurodegenerative disease, is characterized by the selective loss of the dopaminergic neurons in the substantia nigra[1, 2]. PD is characterized by tremor, bradykinesia, rigidity and postural instability [3, 4]. Oxidative stress is considered the most important causal factors of neuronal death in PD [5, 6]. Although its etiology remains unknown, nuclear factor erythroid 2-related factor 2 (Nrf2)/HO-1 pathway has been implicated in the cellular protection against oxidative stress [7-9]. Under basal conditions, Nrf2 is sequestered in the cytoplasm by the inhibitory Kelch-like ECH-associated protein-1 (Keap1). Upon stimulation, Nrf2 dissociates from Keap1 and translocates to the nucleus, where it binds to the antioxidant-response element (ARE), leading to upregulation of several antioxidant enzymes such as $\mathrm{HO}-1$ and various antioxidants.
\end{abstract}

Reports have found that an impaired antioxidant system has been observed in PD, including decreased heme oxygenase-1 (HO-1) expression [10, 11]. HO-1 is an inducible enzyme that has been shown to participate as an essential defensive mechanism for neurons exposed to oxidant challenges, being related to antioxidant defenses in certain neuropathological conditions [12].
7,8-Dihydroxyflavone (7,8-DHF), a member of flavonoid family, has been identified as a selective tyrosine kinase receptor B (TrkB) agonist and exerts potent neuroprotective and neurotrophic effects in Parkinson's disease (PD), and other neurological disorders $[13,14]$. Except activating TrkB receptors, antioxidant property of 7,8-DHF also contributes to its protection against oxidative stress-induced damage [15-17].

Our previous studies have demonstrated that 7,8-DHF protects PC12 cells against 6-OHDA-induced cytotoxicity through its antioxidant action and activating PI3K/Akt [18]. Recently, several studies reported that cytoprotective effects of 7,8-DHF against oxidative stress are associated with the Nrf2-induced expression of HO-1 in lung fibroblasts, keratinocytes and $\mathrm{C} 2 \mathrm{C} 12$ myoblasts $[19,20]$. In the present study, we further elucidated whether HO-1 pathway mediate the protective effect of 7,8-DHF against $\mathrm{MPP}^{+}$-induced PC12 cell injury.

\section{Materials and methods}

2.1 Materials7,8-DHF was purchased from TCI America (USA). Thiazolyl blue tetrazolium bromide (MTT), $\mathrm{MPP}^{+}$and Zinc protoporphyrin IX (ZnPP, a specific inhibitor of HO-1) were Sigma products (St.

This article is published under the terms of the Creative Commons Attribution License 4.0 Author(s) retain the copyright of this article. Publication rights with Alkhaer Publications. Published at: http://www.ijsciences.com/pub/issue/2019-03/

DOI: 10.18483/ijSci.1932; Online ISSN: 2305-3925; Print ISSN: 2410-4477 
Louis, MO, USA). Dulbecco's modified Eagle's medium (DMEM) and fetal bovine serum (FBS) were bought from Hyclone (Logan, USA). Rabbit polyclonal anti-HO-1 was from Santacruz. Rabbit anti- $\beta$-actin was from Bioss Beijing. BCA protein assay kit was from Thermo Fisher Scientific (USA).

2.2 Cell culture The PC12 cells, a Rat pheochromocytoma cell, were supplied by the Type Culture Collection of the Chinese Academy of Sciences (Shanghai, China). The cells were maintained in DMEM supplemented with $10 \%$ FBS, $100 \mathrm{IU} / \mathrm{ml}$ of penicillin and $100 \mu \mathrm{g} / \mathrm{ml}$ of streptomycin at $37^{\circ} \mathrm{C}$ in a humidified atmosphere of $5 \% \mathrm{CO}_{2}$ and $95 \%$ air. It was necessary to change the medium every two or three days. The cells were maintained in 96-well plates (MTT assay) or 6-well plates (Western blotting assay) for indicated times.

\subsection{Determination of cell viability}

The PC12 cells were cultured in 96-well plates at a density of $10^{4} /$ well. Following $24 \mathrm{~h}$ of incubation, the PC12 cells were treated with $\operatorname{MPP}^{+}(100,200,300,400,500 \mu \mathrm{mol} / \mathrm{L})$ for $24 \mathrm{~h}$. And the cells were pretreated with the 7, 8-DHF $(1,5,25 \mu \mathrm{mol} / \mathrm{L})$ for $6 \mathrm{~h}$, then exposed to $\mathrm{MPP}^{+}(400 \mu \mathrm{mol} / \mathrm{L})$ for subsequent $24 \mathrm{~h}$. In some experiments, $\mathrm{ZnPP}(5 \mu \mathrm{mol} / \mathrm{L})$ was added in $7,8-\mathrm{DHF}$ treatment, then send to $\mathrm{MPP}^{+}(400 \mu \mathrm{mol} / \mathrm{L})$. Cell viability was measured by the MTT assay. Briefly, $20 \mu \mathrm{l}$ of MTT solution ( $5 \mathrm{mg} / \mathrm{ml}$ in PBS) was added into each well. Then,the plates were incubated for 4 $\mathrm{h}$ at $37^{\circ} \mathrm{C}$. The dark blue formazan product, the reduction of MTT, was dissolved in $150 \mu \mathrm{l}$ of DMSO. Signal detection was implemented by microplate reader (Molecular Devices, Sunnyvale, CA, USA) at the wavelength of $570 \mathrm{~nm}$. The cell viability was defined as the percentage of the untreated control cells.

\subsection{Western blot analysis}

Total protein was extracted from the PC12 cells. After BCA protein assay, each sample was separated by $10 \%$ sodium dodecyl sulphate polyacrylamide gel electrophoresis (SDS-PAGE) and then transferred to a polyvinylidene difluoride (PVDF) membrane. The membranes were incubated with $10 \%$ nonfat milk to block the non-specific binding sites for $1 \mathrm{~h}$. The membranes were probed with different primary antibodies overnight at $4^{\circ} \mathrm{C}$, followed by incubation with goat anti-rabbit HRP-conjugated secondary antibody for $1 \mathrm{~h}$ at room temperature. Finally, the protein bands were detected by the ECL System (Bio-Rad, USA) and quantified by densitometric analysis using Image $\mathbf{J}$ software.

\subsection{Statistical analysis}

The results were obtained from four to six independent experiments, and presented as means \pm SEM. One-way analysis of variance (ANOVA) followed by Turkey's multiple comparison test was performed to compare the differences between means. Differences were considered statistically significant when $P$ values were less than 0.05 .

\section{Results}

\subsection{Effect of different dosage of $\mathrm{MPP}^{+}$on PC12 cells viability}

We first found the neurotoxic effect of different dosage of $\mathrm{MPP}^{+}$on neuronal differentiated PC12 cells. Our results showed that a decrease in cell viability was induced by $\mathrm{MPP}^{+}$in a concentration-dependent manner. Cell viability was $60 \%$ of control cultures after exposure to $400 \mu \mathrm{mol} / \mathrm{L}$ $\mathrm{MPP}^{+}$for $24 \mathrm{~h}$ (Fig.1). Based on these results, $400 \mu \mathrm{mol} / \mathrm{L} \mathrm{MPP}+$ was used in the following experiments to assess the neuroprotective effect of 7,8-DHF.

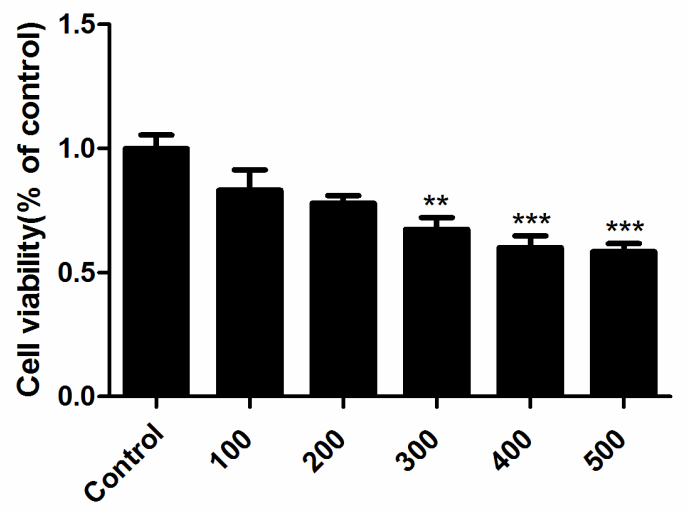

Fig.1 The PC12 cells were exposed to different dosage of $\mathrm{MPP}^{+}(100,200,300,400$, and $500 \mu \mathrm{mol} / \mathrm{L})$ for $24 \mathrm{~h}$. Cell viability was determined by the MTT method. Data are expressed as percentage of values in untreated control cultures, and are the means \pm SD of six separate experiments. ${ }^{* *} P<0.01$ compared with the untreated control, ${ }^{* * *} P<0.001$ compared with the untreated control,

\subsection{Neuroprotective properties of different dosage of 7,8-DHF against $\mathrm{MPP}^{+}$-induced cytotoxicity}

To observe the protective effect of $7,8-\mathrm{DHF}$, the cells were pretreated with $7,8-\mathrm{DHF}(1,5,25 \mu \mathrm{mol} / \mathrm{L})$, then incubated with $\mathrm{MPP}^{+}$for the subsequent $24 \mathrm{~h}$. Following exposure to $\mathrm{MPP}^{+}$alone, cell viability was reduced to approximately $60 \%$ of the control, whereas pretreatment with $7,8-\mathrm{DHF}$ for $6 \mathrm{~h}$ 
dramatically improved the viability up to $87.72 \%$ in a dose-dependent manner (Fig.2). This results suggest that 7,8-DHF pretreatment for $6 \mathrm{~h} \mathrm{might}$ activate intracelluar defense system, leading to more powerful protection against $\mathrm{MPP}^{+}$-induced cytotoxicity and the most effective concentrations was $25 \mu \mathrm{mol} / \mathrm{L}$.

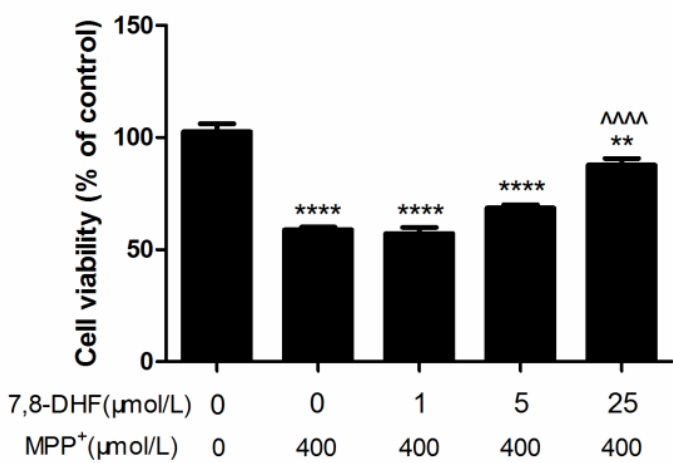

Fig.2 The PC12 cellswere pretreated with various concentration of

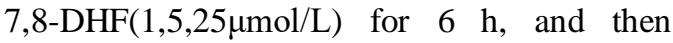
incubated with or without $400 \mu \mathrm{mol} / \mathrm{L} \mathrm{MPP}^{+}$for subsequent $24 \mathrm{~h}$. Cell viability was determined using the MTT assay. The results were obtained from five independent experiments. ${ }^{* *} P<$ $0.01,{ }^{* * * * *} P<0.0001$ compared with the untreated control, ${ }^{M M} P<0.0001$ compared with $\mathrm{MPP}^{+}$group.

3.3 Neuroprotective properties of different dosage of 7,8-DHF against $\mathrm{MPP}^{+}$-induced expression of HO-1

To clarify the involvement of HO-1 signaling pathway in the protective effect of 7,8-DHF, expression of HO-1 was analyzed by Western blot. The results revealed that pretreatment with 7,8-DHF for $6 \mathrm{~h}$ enhanced the HO-1 level induced by $\mathrm{MPP}^{+}$. We also found that the upregulation of $\mathrm{HO}-1$ expression by 7,8-DHF was also dose-dependent (Fig 3 ). This results suggest that 7,8-DHF pretreatment for $6 \mathrm{~h}$ might activate HO-1 signaling pathway, leading to more powerful protection against $\mathrm{MPP}^{+}$-induced cytotoxicitymol.

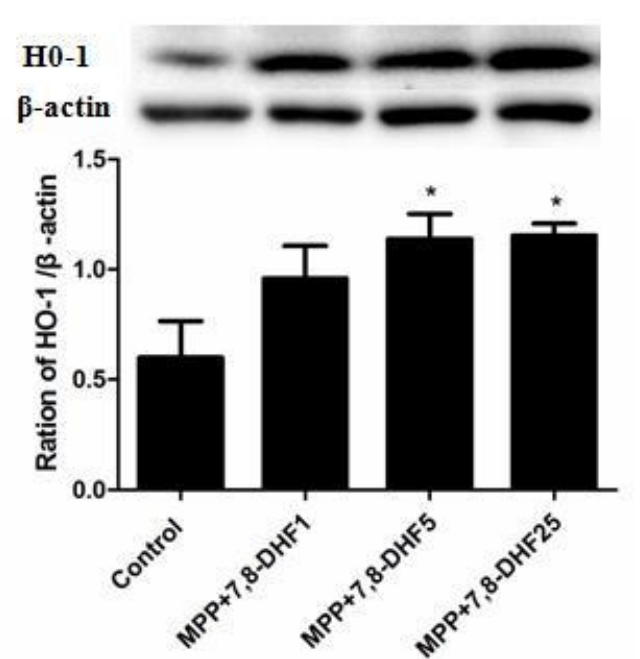

Fig.3 The PC12 cells were treated with $7,8-\mathrm{DHF}(1,5,25 \mu \mathrm{mol} / \mathrm{L})$ for $6 \mathrm{~h}$ and then exposed in $400 \mu \mathrm{mol} / \mathrm{L} \mathrm{MPP}^{+}$for subsequent $24 \mathrm{~h}$. The HO-1 protein levels were estimated by Western blot. The results were expressed by the ratio of target proteins to $\beta$-actin and obtained from six independent experiments.. ${ }^{*} P<0.05$ compared with the control.

\subsection{Blocking effect of HO-1 inhibitor on protection by 7,8-DHF}

To confirm that the protective effects of 7,8-DHF are mediated through the activation of HO-1 pathway, the PC12 cells were pretreated with $\mathrm{ZnPP}$, a specific HO-1 inhibitor, and 7,8-DHF before the incubation of $\mathrm{MPP}^{+}$, the cell viability was then assessed. 7,8-DHF abrogated the cell injury induced by $\mathrm{MPP}^{+}$, and this protective effect were partially blocked by $\mathrm{ZnPP}$ (Fig 4). These results suggest that HO-1 might be involved in the protective effect of 7,8-DHF.

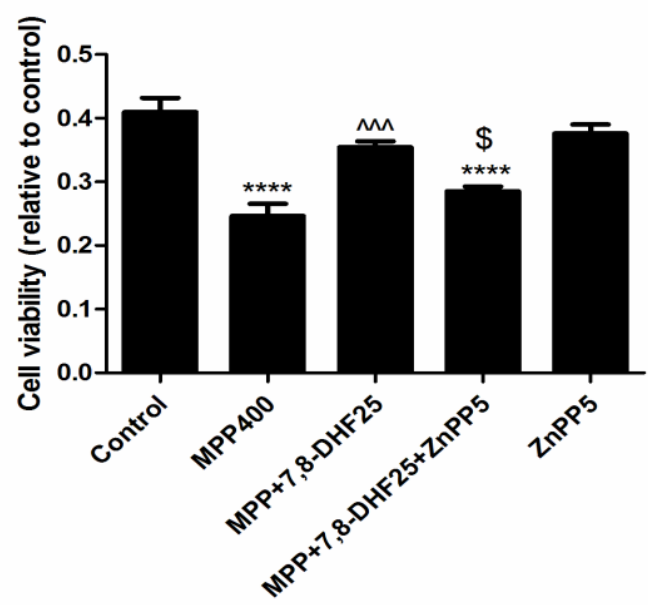

Fig.4 The PC12 cells were pretreated respectively with $\mathrm{ZnPP}(5 \mu \mathrm{mol} / \mathrm{L})$ and $7,8-\mathrm{DHF}(25 \mu \mathrm{mol} / \mathrm{L})$ for $6 \mathrm{~h}$, then incubated 
with $\mathrm{MPP}^{+}(400 \mu \mathrm{M})$ for $24 \mathrm{~h}$. The cell viability was estimated by the MTT assay. The results are obtained from six independent experiments. ${ }^{* * * *} P<0.0001$ compared with the control, ${ }^{M} P<0.001$ compared with $\mathrm{MPP}^{+}$ group, ${ }^{\$} P<0.05$ compared with $\mathrm{MPP}^{+}$group+7,8-DHF

\section{Discussion}

There is growing evidence that 7,8-DHF exerts neuroprotection by acting as a potent antioxidant [15-17]. 7,8-DHF is considered as a direct free radical scavenger due to two adjacent hydroxyl groups as electron donors [21, 22]. Our previous study also showed that the protective effect of 7,8-DHF in 6-OHDA-treated PC12 cells are associated with increased HO-1 activation [18]. In conclusion, the protective effect of 7,8-DHF was closely associated with its antioxidant property. Recently, 7,8-DHF has been reported to activate Akt and ERK-dependent $\mathrm{Nrf} 2$ signaling cascades in cultured human $\mathrm{HaCaT}$ keratinocytes and lung fibroblasts [23], leading to the up-regulation of HO-1 and cytoprotection against oxidative stress. Therefore, it is likely that $\mathrm{Nrf2} / \mathrm{HO}-1$ pathway might be involved in the protective effect of $7,8-\mathrm{DHF}$ in $\mathrm{MPP}^{+}$-induced PC12 cells injury.

1-Methyl-4-phenyl-1,2,3,6-tetrahydropyridine (MPTP) induces toxicity through its conversion of astrocytes to $\mathrm{MPP}^{+}$in the reaction catalyzed by monoamine oxidase type B (MAO-B) [24]. MPP+ is selectively transported into the dopaminergic neurons through a high-affinity dopamine (DA) transporter and accumulates in the neuronal mitochondria increases sensitivity to oxidative attack, and eventually causes apoptotic or necrotic neuronal cell death. In this study, we observed that exposure to $\mathrm{MPP}^{+}$markedly reduced the PC12 cells viability and increased the HO-1 levels $[25,26]$. However, these effects were suppressed by pretreatment with 7,8-DHF.

Elevated HO-1 expression levels are involved in antioxidant defense in Parkinson disease patients [27]. Accumulating evidence has demonstrated that activation of HO-1 pathway plays a central role in cellular antioxidant defense [7, 28, 29]. Under normal conditions, Nrf2 was bonded in the plasma with Keap1, which facilitate the ubiquitination and subsequent proteolysis of Nrf2.Once exposure to various types of stress, the Nrf2/Keap1 complex is dissociated, leading to the phosphorylation of Nrf2, a critical process in the nuclear translocation of Nrf2 and activation of target genes including HO-1. In our study, although 7,8-DHF did not increase the whole cell levels of $\mathrm{Nrf} 2$, it facilitated the translocation of
Nrf2 to the nuclear, increasing the HO-1 expression. These results show treatment with 7,8-DHF activate $\mathrm{Nr} 2 / \mathrm{HO}-1$ in PC12 cells.

Using the MTT assay, it was found that pretreatment with $\mathrm{ZnPP}$, a HO-1 inhibitor, markedly blocked the protection by 7,8-DHF after exposure to $\mathrm{MPP}^{+}$. These results suggest that Nrf2-dependent induction of HO-1 may, at least in part, participate the protection by 7,8-DHF in $\mathrm{MPP}^{+}$-injured PC12 cells. Qinyong Ye et al reported that astaxanthin protects against $\mathrm{MPP}^{+}$-induced oxidative stress by the HO-1/NOX2 axis in the PC12 cells [30]. Jiang et al reported that gastrodin protects against $\mathrm{MPP}^{+}$-induced oxidative stress by upregulation of HO-1 through p38 MAPK/Nrf2 pathway in hu man dopaminergic cells [31]. Lee et al found that sulfuretin that the cytoprotective effect of sulfuretin against tert-butyl hydroperoxide-induced hepatotoxicity through Nrf2/ARE and JNK/ERK MAPK-mediated HO-1 expression [32]. These findings suggest that the protein kinase-mediated activation of Nrf2/HO-1 pathway may be specific to the stimulus and cell type.

As expected, 7,8-DHF alone markedly elevated the HO-1 levels, and pretreatment with ZnPP attenuated 7,8-DHF-induced HO-1 expression. These results suggest that neuroprotective properties was mediated by the HO- 1 signaling pathways, and the HO-1-induced upregulation are involved in the protection by $7,8-\mathrm{DHF}$ against $\mathrm{MPP}^{+}$-induced cell injury in PC12 cells.

In conclusion, the present study demonstrated that 7,8-DHF activated the intracellular defense systems through HO-1, and improves the survival of PC12 cells treated with $\mathrm{MPP}^{+}$. 7,8-DHF, acting as a small-molecule TrkB agonist and potent antioxidant, might be promising candidate for the therapy of neurological diseases.

\section{References}

1. Lang, A.E., The progression of Parkinson disease: a hypothesis. Neurology, 2007. 68(12): p. 948-52.

2. Langston, J.W., The Parkinson's complex: parkinsonism is just the tip of the iceberg. Ann Neurol, 2006. 59(4): p. 591-6.

3. Olanow, C.W. and W.G. Tatton, Etiology and pathogenesis of Parkinson's disease. Annu Rev Neurosci, 1999. 22: p. 123-44.

4. Vila, M. and S. Przedborski, Genetic clues to the pathogenesis of Parkinson's disease. Nat Med, 2004. 10 Suppl: p. S58-62.

5. Schapira, A.H., Mitochondria in the aetiology and pathogenesis of Parkinson's disease. Lancet Neurol, 2008. 7(1): p. 97-109.

6. Schulz, J.B., Update on the pathogenesis of Parkinson's disease. J Neurol, 2008. 255 Suppl 5: p. 3-7.

7. Surh, Y.J. and H.K. Na, NF-kappaB and Nrf2 as prime molecular targets for chemoprevention and cytoprotection with anti-inflammatory and antioxidant phytochemicals. Genes Nutr, 2008. 2(4): p. 313-7. 
8. Kweon, M.H., et al., Constitutive overexpression of Nrf2-dependent heme oxygenase-1 in A549 cells contributes to resistance to apoptosis induced by epigallocatechin 3-gallate. J Biol Chem, 2006. 281(44): p. 33761-72.

9. Niture, S.K., R. Khatri, and A.K. Jaiswal, Regulation of Nrf2-an update. Free Radic Biol Med, 2014. 66: p. 36-44.

10. Khurana, N. and A. Gajbhiye, Ameliorative effect of Sida cordifolia in rotenone induced oxidative stress model of Parkinson's disease. Neurotoxicology, 2013. 39: p. 57-64.

11. Lu, S.H., T.H. Chen, and T.C. Chou, Magnolol Inhibits RANKL-induced osteoclast differentiation of raw 264.7 macrophages through heme oxygenase-1-dependent inhibition of NFATc1 expression. J Nat Prod, 2015. 78(1): p. 61-8.

12. Neis, V.B., et al., Involvement of Heme Oxygenase-1 in Neuropsychiatric and Neurodegenerative Diseases. Curr Pharm Des, 2018. 24(20): p. 2283-2302.

13. Devi, L. and M. Ohno, TrkB reduction exacerbates Alzheimer's disease-like signaling aberrations and memory deficits without affecting beta-amyloidosis in 5XFAD mice. Transl Psychiatry, 2015. 5: p. e562.

14. Jang, S.W., et al., Deoxygedunin, a natural product with potent neurotrophic activity in mice. PLoS One, 2010. 5(7): p. e11528.

15. Gupta, V.K., et al., Protective effects of 7,8-dihydroxyflavone on retinal ganglion and $R G C-5$ cells against excitotoxic and oxidative stress. J Mol Neurosci, 2013. 49(1): p. 96-104.

16. Chen, J., et al., Antioxidant activity of 7,8-dihydroxyflavone provides neuroprotection against glutamate-induced toxicity. Neurosci Lett, 2011. 499(3): p. 181-5.

17. Zhang, R., et al., Preventive effect of 7,8-dihydroxyflavone against oxidative stress induced genotoxicity. Biol Pharm Bull, 2009. 32(2): p. 166-71.

18. Han, X., et al., Antioxidant action of 7,8-dihydroxyflavone protects $\mathrm{PC} 12$ cells against 6-hydroxydopamine-induced cytotoxicity. Neurochem Int, 2014. 64: p. 18-23.

19. Kang, J.S., et al., Schisandrae semen essential oil attenuates oxidative stress-induced cell damage in C2C12 murine skeletal muscle cells through Nrf2mediated upregulation of HO1. Int J Mol Med, 2015. 35(2): p. 453-9.

20. Ryu, M.J., et al., 7,8-Dihydroxyflavone protects human keratinocytes against oxidative stress-induced cell damage via the ERK and PI3K/Akt-mediated Nrf2/HO-1 signaling pathways. Int J Mol Med, 2014. 33(4): p. 964-70.
21. Woldu, A.S. and J. Mai, A novel relationship between the radical-scavenging activity of flavonoids and enthalpy of formation revealed with Hartree-Fock computations and thermochemical deduction. Redox Rep, 2012. 17(3): p. 115-30.

22. Melidou, M., K. Riganakos, and D. Galaris, Protection against nuclear DNA damage offered by flavonoids in cells exposed to hydrogen peroxide: the role of iron chelation. Free Radic Biol Med, 2005. 39(12): p. 1591-600.

23. Ryu, M.J., et al., Effect of 7, 8-dihydroxyflavone on the up-regulation of Nrf2-mediated heme oxygenase-1 expression in hamster lung fibroblasts. In Vitro Cell Dev Biol Anim, 2014. 50(6): p. 549-54.

24. Singer, T.P., et al., Biochemical events in the development of parkinsonism induced by 1-methyl-4-phenyl-1,2,3,6-tetrahydropyridine. J Neurochem, 1987. 49(1): p. 1-8

25. Nicklas, W.J., I. Vyas, and R.E. Heikkila, Inhibition of NADH-linked oxidation in brain mitochondria by 1-methyl-4-phenyl-pyridine, a metabolite of the neurotoxin, 1-methyl-4-phenyl-1,2,5,6-tetrahydropyridine. Life Sci, 1985. 36(26): p. 2503-8.

26. Mizuno, Y., et al., Inhibition of mitochondrial respiration by 1-methyl-4-phenyl-1,2,3,6-tetrahydropyridine (MPTP) in mouse brain in vivo. Neurosci Lett, 1988. 91(3): p. 349-53.

27. Gorojod, R.M., et al., Heme Oxygenase-1 protects astroglia against manganese-induced oxidative injury by regulating mitochondrial quality control. Toxicol Lett, 2018. 295: p. 357-368

28. Kaspar, J.W., S.K. Niture, and A.K. Jaiswal, Nrf2:INrf2 (Keapl) signaling in oxidative stress. Free Radic Biol Med, 2009. 47(9): p. 1304-9.

29. Jaiswal, A.K., Nrf2 signaling in coordinated activation of antioxidant gene expression. Free Radic Biol Med, 2004. 36(10): p. 1199-207.

30. Ye, Q., et al., Astaxanthin protects against $M P P(+)$-induced oxidative stress in PC12 cells via the HO-1/NOX2 axis. BMC Neurosci, 2012. 13: p. 156

31. Jiang, G., et al., Gastrodin protects against MPP(+)-induced oxidative stress by up regulates heme oxygenase-1 expression through p38 MAPK/Nrf2 pathway in human dopaminergic cells. Neurochem Int, 2014. 75: p. 79-88.

32. Lee, C., et al., Attenuation of beta-amyloid-induced oxidative cell death by sulforaphane via activation of NF-E2-related factor 2. Oxid Med Cell Longev, 2013. 2013: p. 313510. 